\title{
Challenges to be overcome: Current situation involving smoking cessation in Dental setting
}

\author{
Desafios a serem superados: situação atual envolvendo cessação do tabagismo no cenário odontológico
}

\begin{abstract}
Adriana Ávila de ALMEIDA ${ }^{1}$, Celso Muller BANDEIRA ${ }^{1}$, Celina Faig Lima CARTA ${ }^{2}$, Estela KAMINAGAKURA ${ }^{1}$, Janete Dias ALMEIDA ${ }^{1}$ 1 - São Paulo State University (Unesp) - Institute of Science and Technology - São José dos Campos - Department of Biosciences and Oral Diagnosis - SP - Brazil.

2 - University of Braz Cubas - School of Dentistry - Mogi das Cruzes - SP - Brazil.
\end{abstract}

\section{ABSTRACT}

Objective: Tobacco use is the leading cause of preventable illness in the world. The dental office represents an opportunity to smokers approach tobacco use control. Despite this well-known statement tobacco use cessation intervention delivered by dentists remain less explored than expected. This study evaluated published articles about interventions delivered by dentists and dental healthcare professionals on smoking cessation and discusses the barriers to be overcome to achieve this goal. Material and Methods: The Medline (PubMed), Scopus, Web of Science, Cochrane Reviews, LILACS and Google Scholar databases were searched for articles published in English between January 2010 and December 2016 using the following MeSH terms keywords: tobacco use cessation, smoking cessation, tobacco use disorder and dentistry. Complementary hand searching was done checking bibliographic references for potentially articles. Results: Seventy-two publications were eligible and the results were divided into eight categories: 1) the role of dentists in tobacco use control; 2) knowledge about tobacco use treatment and interventions; 3) characteristics of the dentist's approach to smokers; 4) barriers and facilitators; 5) future interventions for smoking cessation, 6) reimbursement for tobacco interventions, 7) surveys and 8) systematic reviews or guidelines Conclusion: Dentists play an important role in the prevention and control of smoking. Training in tobacco use cessation has been increased in the past few decades. Teaching how to deal with smoking in undergraduate courses should be a priority for the next few years, so that a new generation of dentists will incorporate into their

\section{RESUMO}

Objetivo: O uso do tabaco é a principal causa de doenças evitáveis no mundo. A consulta odontológica representa uma oportunidade de abordar os fumantes no controle do uso do tabaco. Embora esta conclusão seja bem conhecida, a intervenção para cessação tabágica entre dentistas permanece menos explorada do que o esperado. Este estudo avaliou artigos publicados sobre intervenções entre dentistas e profissionais de saúde dentária na cessação do tabagismo e discute as barreiras a serem superadas para atingir esse objetivo. Material e Métodos: As bases de dados Medline (PubMed), Scopus, Web of Science, Cochrane Reviews, LILACS e Google Scholar foram pesquisadas por artigos publicados em inglês entre janeiro de 2010 e dezembro de 2016 usando os seguintes termos MeSH: tobacco use cessation, smoking cessation, tobacco use disorder and dentistry. A busca manual complementar para potenciais artigos foi feita verificando-se referências bibliográficas. Resultados: setenta e duas publicações foram elegíveis e os resultados foram divididos em oito categorias: 1 ) o papel dos dentistas no controle do uso do tabaco; 2) conhecimento sobre tratamento e intervenções sobre uso do tabaco; 3) características da abordagem do dentista aos fumantes; 4) barreiras e facilitadores; 5) intervenções futuras para cessação do tabagismo, 6) reembolso de intervenções de tabaco, 7) pesquisas e 8) revisões sistemáticas e diretrizes. Conclusão: Os dentistas desempenham um papel importante na prevenção e controle do tabagismo. O treinamento na cessação do uso do tabaco tem aumentado nas últimas décadas. Ensinar a lidar com o tabagismo em cursos de graduação deve ser uma prioridade para os próximos anos, de modo que uma nova geração de dentistas incorpore 
habitual activities a natural and efficient approach to smokers.

\section{KEYWORDS}

Dentistry; Tobacco use cessation; Tobacco use disorder. em suas atividades habituais uma abordagem natural e eficiente para os fumantes.

\section{PALAVRAS-CHAVE}

Odontologia; Abandono do uso de tabaco; Tabagismo.

\section{INTRODUCTION}

A ccording to the World Health Organization (WHO), tobacco use is a chronic and recurrent disease caused by nicotine dependence and is the leading cause of preventable death in the world. The prolonged use of tobacco and its derivatives alone is an important risk factor for more than 50 diseases, including cancer [1]. Tobacco and its derivatives were responsible for 100 million deaths in the 20th century and is estimated that approximately one billion deaths will occur until the end of this century [2]. Onethird of the adult world population is exposed to passive smoking, which kills an additional 600,000 individuals every year $[3,4]$.

Among doctors, nurses, dentists and other healthcare professionals, the contact with smokers is a practical and appropriate opportunity for tobacco use control. The minimum approach or intervention recommended by the WHO is based on the 5 A's intervention (ask, advise, assess, assist, and arrange). This method is indicated for all healthcare professionals and might be the starting up moment of contact with the patient, permitting the initial motivation on tobacco use cessation [5-7].

The systemic clinical manifestations of smoking are often recognized only after years of use. However, oral alterations can be detected early, especially on young users as teenagers. Regular visits to the dentist are therefore a great opportunity to identify oral diseases related to the use of tobacco and are appropriate to encourage the patient to stop smoking $[8,9]$.
Nevertheless, these actions are still poorly explored and controversial. In the last years, several studies using questionnaires on tobacco cessation measures applied to dentists have been published [7,9-15]. These studies have shown that, although dentists agree that smoking is an important risk factor for oral diseases including oral cancer, they are not prepared to treat patients because of lack of knowledge or desire to do so and approaches could therefore be more efficient [7,9-16]. The arguments reported by dentists include the lack of training and time, the view that they would not be able to convince their patients to quit smoking, the fear of disturbing the patient who could be not interested on smoking cessation and the lack of reimbursement by the health system for more complex care.

In view of this scenario, it is important to revise the current key concepts of tobacco use cessation on dental setting and to highlight the value of the dentist as a professional that can markedly influence tobacco use cessation and control.

\section{MATERIAL AND METHODS}

In this study, we conducted a review of literature on the main aspects related to education provided and interventions delivered by dentists and dental healthcare professionals about smoking cessation. The databases Medline (PubMed), Scopus, Web of Science, Cochrane Reviews, LILACS and Google Scholar were searched for complete articles published in English between January 2010 and December 2016 using the following MeSH keywords: tobacco use cessation, smoking cessation, 
tobacco use disorder and dentistry using the search strategy: ("Tobacco Use Cessation" OR "Smoking Cessation") AND "Tobacco Use Disorder" AND "Dentistry". Two authors analyzed the collected data independently. Discrepancies in extracted data were resolved by consensus.

Studies with different designs were included since they included undergraduate dental students, dentists, dental hygienists or dental faculty members. The studies should enclose any reference about tobacco cessation education offered in dental curriculum, models of tobacco use cessation delivered by dentists, including the approach to the smoker, evaluations of dentist's knowledge and attitudes about conducting tobacco use cessation, evaluation of smoking profile and tobacco use therapy. Due to the focus of these review, case reports or clinical studies involving tobacco related oral diseases were excluded even if there mentioned tobacco cessation.

Firstly, all the titles and abstracts from selected articles were evaluated and publications that did not fit the inclusion criteria were excluded. Out of 91 articles found, 19 were excluded given that they were not directly related to the topic or were duplicated. At the end, seventy-two studies met the inclusion criteria (Figure 1, Figure 2 and Table I).

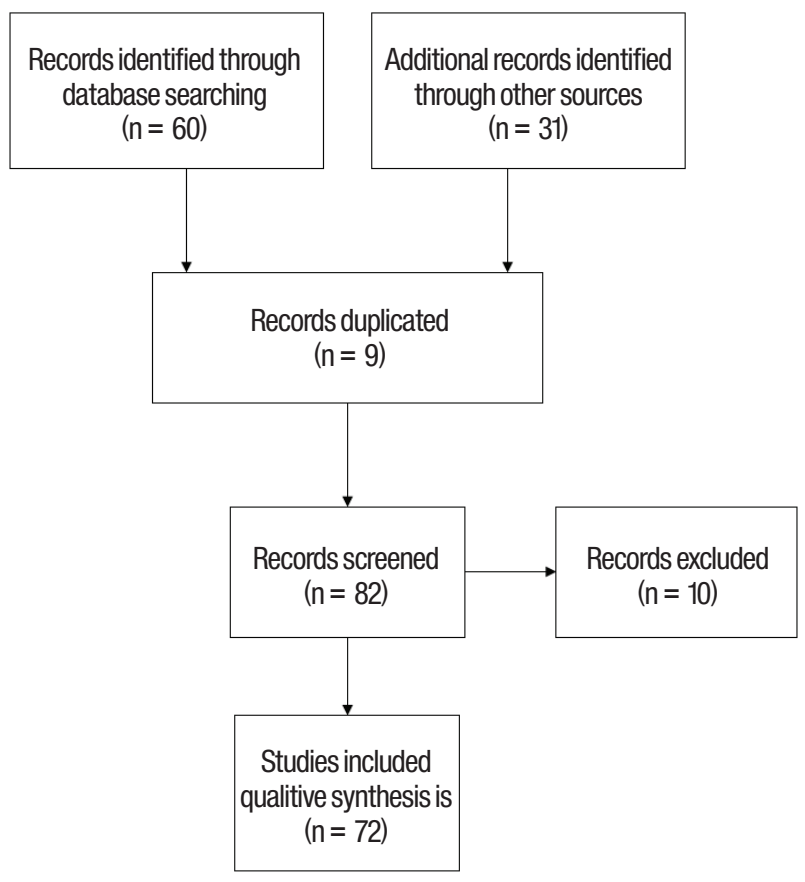

Figure 1 - Fluxogram of selected articles.

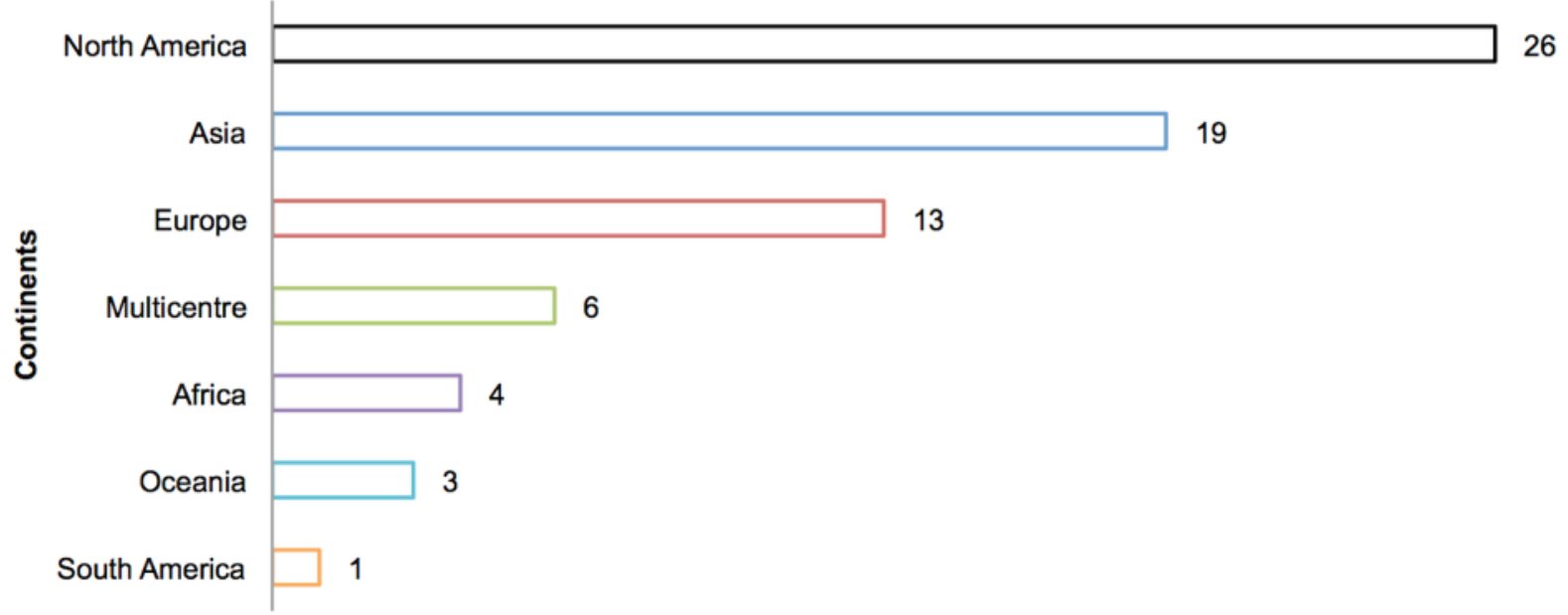

Number of articles

Figure 2 - Chart with the eligible articles classified based on continents. 
Table I - Eligible articles classified per year and country

\begin{tabular}{|c|c|c|}
\hline Year & Authors & Country \\
\hline 2010 & Chestnutt IG & USA \\
\hline 2010 & Davis et al. & Multicenter \\
\hline 2010 & Gonseth et al. & Switzerland \\
\hline 2010 & Gordon etal. & USA \\
\hline 2010 & Gordon etal. & USA \\
\hline 2010 & Hanioka et al. & Japan \\
\hline 2010 & Needleman et al. & Multicenter \\
\hline 2010 & O'Donell et al. & USA \\
\hline 2010 & Ramseier etal. & Multicenter \\
\hline 2010 & Rankin etal. & USA \\
\hline 2010 & Tong et al. & USA \\
\hline 2011 & Amemori et al. & Finland \\
\hline 2011 & Arnettet al. & USA \\
\hline 2011 & Chandrashekar et al. & India \\
\hline 2011 & Ehizele et al. & Nigeria \\
\hline 2011 & Miller et al. & USA \\
\hline 2011 & Morgan et al. & USA \\
\hline 2011 & Nasser M & UK \\
\hline 2011 & Patel et al. & USA \\
\hline 2011 & Pau et al. & UK \\
\hline 2011 & Rosa et al. & Brazil \\
\hline 2011 & Rosseel et al. & The Netherlands \\
\hline 2011 & Shelley et al. & USA \\
\hline 2011 & Studts etal. & USA \\
\hline 2011 & Utietal. & Nigeria \\
\hline 2012 & Albert and Ward & USA \\
\hline 2012 & Andersson etal. & Sweden \\
\hline 2012 & Arnettetal. & USA \\
\hline 2012 & Carr and Ebbert & USA \\
\hline 2012 & Carson et al. & UK \\
\hline 2012 & Matias et al. & Multicenter \\
\hline 2012 & Murugaboopathy et al. & India \\
\hline 2012 & Pai and Prasad & India \\
\hline 2012 & Shelley et al. & USA \\
\hline 2012 & Sinha et al. & India \\
\hline 2012 & Venkatesh and Sinha & India \\
\hline 2013 & Antal etal. & Hungary \\
\hline 2013 & Dawson et al. & Australia \\
\hline 2013 & Kadanakuppe and Aradhya & India \\
\hline 2013 & McNeely etal. & USA \\
\hline 2013 & Montini et al. & USA \\
\hline
\end{tabular}

\begin{tabular}{|c|c|c|}
\hline Year & Authors & Country \\
\hline 2013 & Parakh et al. & India \\
\hline 2013 & Pizzo et al. & Italy \\
\hline 2013 & Prakash et al. & USA \\
\hline 2013 & Ramseier etal. & Switzerland \\
\hline 2013 & Rindal et al. & Multicenter \\
\hline 2014 & Agaku and Ayo-Yusuf & South Africa \\
\hline 2014 & Ahmady et al. & Islamic Republic of Iran \\
\hline 2014 & Dable et al. & India \\
\hline 2014 & Doucette et al. & Canadá \\
\hline 2014 & Jannat-Khah etal. & USA \\
\hline 2014 & Nordin et al. & Malaysia \\
\hline 2014 & Oberoi et al. & India \\
\hline 2014 & Oberoi et al. & India \\
\hline 2014 & Ostroff et al. & USA \\
\hline 2014 & Raja et al. & India \\
\hline 2014 & Romito et al. & USA \\
\hline 2014 & Singla et al. & India \\
\hline 2014 & Singleton etal. & USA \\
\hline 2014 & Uti et al. & Nigeria \\
\hline 2015 & Ajagannanavar et al. & India \\
\hline 2015 & Awan eta. & Saudi Arabia \\
\hline 2015 & Ford et al. & Australia \\
\hline 2015 & Ford et al. & Australia \\
\hline 2015 & Mackie et al. & USA \\
\hline 2015 & Ramseier etal. & Multicenter \\
\hline 2015 & Shaheen et al. & India \\
\hline 2015 & Stassen etal. & Ireland \\
\hline 2015 & Sventanoff et al. & USA \\
\hline 2015 & Tahani et al. & Iran \\
\hline 2015 & Virtanen et al. & Sweden \\
\hline 2016 & Omaña-Cepeda et al. & Spain \\
\hline
\end{tabular}

Due to the different aspects found in our search, the eligible articles were divided into eight categories: the role of dentists in tobacco use control; knowledge about tobacco use treatment and interventions; characteristics of the dentist's approach to smokers; barriers and facilitators; future interventions for smoking cessation, reimbursement for tobacco interventions, Surveys and Systematic reviews or guidelines. 


\section{RESULTS}

\section{control \\ The role of dentists in tobacco use}

Dentists are health professionals that are fully trained to educate patients about the harmful effects of smoking, promote counseling, and help those who want to quit smoking. During a visit to the dentist, it is possible to observe the effects of tobacco use even in patients who have smoked for a short period. Tobacco use is associated with several oral diseases such as periodontal disease, tooth loss, an unsatisfactory response to implants, gingivitis and oral cancer. However, the potential of these professionals in tobacco use control during daily clinical practice remains an unexplored field [7,17-21].

Given their position they can increase the chances of behavioral changes of patients in favor of trying to quit smoking. The demonstration of a cause-effect relationship between oral alterations and tobacco use and the benefits of dental treatment may encourage patients to quit smoking. Interventions performed by oral health professionals are effective and can improve the knowledge about the risks of smoking and increase tobacco abstinence rates [14,22-32].

\section{Knowledge about tobacco use treatment and interventions}

Tobacco use is a chronic recurrent disease of multifactorial etiology, in which the reward system of the brain plays a key role in the smoker's behavior [33]. Reports of multiple previous unsuccessful attempts of tobacco use cessation illustrate the addictive character of this disease. Knowledge of these aspects during tobacco therapy contributes to obtain satisfactory and long-lasting results [33].

Learning the definitions and concepts of different aspects of smoking cessation increases the confidence and self-efficacy of professionals that deal with smokers. This training should also be included in the undergraduate course and education curriculum of dental students [32]. Some studies evaluating the impact of new training techniques on tobacco cessation interventions among dental students have reported satisfactory results [15,25,26,34-39].

The lack of previous knowledge of dentists about the topic is one of the main reasons for the few interventions aimed at smokers. In this respect, the possibility of tobacco-dependence education will extend the quality and quantity of interventions and monitoring [7,9$13,24,28,31,32,38-40]$.

\section{General characteristics of the dentist's} approach to smokers

Chestnutt [41] and Albert and Ward [42] have demonstrated the importance of dentists for tobacco use cessation in the world. Dentists can easily diagnose oral diseases caused by tobacco. These diseases justify an approach targeting smokers in order to obtain a satisfactory response [8]. Both short-term and structured interventions have shown positive effects on reducing tobacco consumption $[17,23,25,26,38,40]$.

The expansion of the undergraduate curriculum, including a larger number of theoretical and practical classes on tobacco use, has proven effective and promising in increasing the number of smokers attended by oral health professionals $[20,31,32,39,43-45]$.

\section{Barriers and facilitators to tobacco use} cessation in dentistry

Dentist's justifications for the small number of interventions involving smokers have been studied. They include the lack of time, fear of the patient's reaction or resistance in accepting the approach, fear that the patient will lose trust in the professional, difficulty in addressing the topic, also being a smoker, lack of knowledge about the topic, lack of 
reimbursement, and fear of the reaction of colleagues [9,14,16,17,27,28,39,41-43,46-56]. Once receiving training on tobacco cessation the graduation students and dental health professionals perceive significantly reduction on the pointed barriers [43].

Factors facilitating the approach to smokers are the presence of electronic reports for the addition of information about tobacco use, identification of oral diseases related to smoking, use of questionnaires for the evaluation of smoking, use of support material, reimbursement for the interventions, and experience as an ex-smoker $[9,16,17,46,57]$.

\section{Future interventions for smoking cessation delivered by dentists}

New studies to evaluate strategies that could increase tobacco cessation interventions bydentists are being conducted [5,20,24,57,58]. Amemori et al. [59] postulated that behavior change interventions should be implemented among dentists to increase adherence to current consensuses, thus modifying existing beliefs and barriers. Similarly, Gonseth et al. [60] reported that multidisciplinary programs of tobacco cessation involving physicians and dentists could be suitable and productive.

Oberoi et al. [29] discuss the importance of new interventions on tobacco cessation delivered by oral health professionals such as setting up 24 hours quit-lines, providing nicotine replacement therapy, more certified courses and training on tobacco cessation, extending the tobacco cessation services to the rural community and develop mobile oral health services which includes tobacco related education and oral health.

\section{Reimbursement of dentists for tobacco interventions}

One of the barriers cited by dentists to improve tobacco control conducts is the lack of reimbursement by health plans for an intervention that demands time and material
$[7,9,10,13,15,16,34,42,56]$. Shelley et al. [61] in a study involving 11 American insurance company executives addressed this fact. The study showed that research and interventions for tobacco cessation are appropriate for routine dental practice. However, a larger number of studies are necessary to confirm the efficacy of these approaches in order to justify the investment in provider reimbursement.

\section{Surveys}

Most of the aspects of the education provided and interventions delivered by dentists and dental health care professionals were evaluated by surveys. Important aspects such awareness, attitude, practices, willingness and barriers were evaluated using hand-delivered, self-administered or via electronic contact were searched. Studies were conducted in many different clusters like dental universities [62], dental health professionals $[7,9,12,13,17,32,46,48,50-52,55,56,63-65]$, dental insurance companies [61], students [1 $5,21,28,31,32,38,39,45,47,49,51,53,55,66]$, dental patients who use tobacco $[30,67,68]$ and dental teachers [44].

\section{Systematic Reviews}

Illustrating the awareness of the scientific community about this issue and the importance of the problem on oral health are described in the systematic reviews [5,11,19,22,27,69$72]$ and guidelines [18,42,58,73] published about tobacco use cessation in dental setting compelling the best evidences and giving advices about the needs in this area.

\section{DISCUSSION}

Dentists are in a favorable position to play an important role in the control of chronic tobacco dependence, particularly in pregnant women and young people [28]. Although the scope of these attitudes may have a positive impact on oral health and cancer prevention, much remains unexplored and needs to be improved. 
Even though the global awareness about tobacco use has been worldwide discussed the health problem is still a big challenge for many countries. Although still represent a minor number of studies, tobacco cessation counseling has been considered an important theme into dental publications over the past decades [74]. Studies demonstrating the importance of dentists for the approach to smokers, support of tobacco use cessation or prevention of severe diseases such as oral cancer have been published in recent years. The beliefs of failure and incapacity to treat smokers are related to the lack of adequate undergraduate training [51]. The concept that tobacco education and cessation are not a responsibility for dental professional still remains a great barrier for the improvement in this area [51].

Many systematic reviews established that trained dental health professionals who had received training were more likely to execute task related to tobacco use cessation than untrained controls [22,69-71]. Recent publication from Cochrane has demonstrated that individual counseling was more effective than a minimal contact control (brief advice, usual care, or provision of self-help materials) and can assist smokers to quit. Thus, there are strong evidences that training can provide more self-confidence among dental health professional allowing them to deliver individual interventions for their smoking patients [75].

In view of the world panorama of tobacco consumption and its devastating health consequences, the WHO coordinates and supports global initiatives of tobacco control $[76,77]$. Guidelines on tobacco use have been available for more than a decade, but systematic reviews involving tobacco use cessation in the dental setting have only been published in recent years [22,27,69-71]. The inclusion of dentists in the guidelines for tobacco control is emphasized since the maintenance of oral health is directly related to the cessation of the use of tobacco and its derivatives. Furthermore, the training and commitment of dental professionals with smokers is important. Evaluation of students' and dentists' knowledge about tobacco use treatment reveals a gap between the number of patients attended and the lack of tobacco-dependence education for the continuation of treatment. Studies evaluating different forms of student training showed an increase in approaches in addition to greater comfort and confidence in the interventions for smokers [20,34-37]. Thus, reassessment of the training of dental students regarding the study of tobacco use in the graduation curricula is necessary $[28,44,45]$.

It is necessary that the concepts of such a complex disease be aligned with the progressive contact of the student with the smoking patient. The student will thus gain self-confidence and the capacity to satisfactorily attend the patient from the first contact, with the patient being prepared to quit smoking or not, until definitive abstinence. The healthcare professional is committed to the comprehensive evaluation of the individual. It would be correct to say that we should treat an individual and not the disease; thus, the approach to smokers in medicine and dentistry should be part of the treatment [73]. The smoker often wants to quit smoking, but the addictive nature of the disease makes it difficult to remain abstinent without support. More than the physician, the dentist frequently has recurring meetings with patients who smoke and misses the opportunity to support this cessation.

Oral diseases related to tobacco use are themselves a major incentive so that the dentist continuously encourages the patient to quit smoking since the success of treatment depends on it. Appropriate treatment of periodontal diseases, disorders with the potential of malignant transformation and cancer are concrete reasons for the dentist to support the patient to quit smoking. Similarly, aesthetic treatment will not have the expected effect if the patient does not stop smoking $[8,42]$. One important aspect to be considered is the cancer patient who remains smoking once this attitude attitude may have a negative impact on their treatment and outcome. In a recent study 
Tamí-Maury et al. [78] showed that, despite 91\% of the dentists from Texas provide care to cancer patients, one third do not provide brief interventions or assist tobacco users to quit among those cancer patients and survivors.

For this reason, dentists are fundamental for the expansion of tobacco control measures in the world and their participation in multidisciplinary teams for smoker support is of paramount importance. Teaching how to deal with the main aspects of smoking in undergraduate courses should be a priority for the next few years, so that a new generation of dentists will incorporate into their habitual activities a natural and efficient approach to smokers. This attitude is important not only for dental treatment in general, but also for the wellbeing of the patient. Further studies addressing different aspects of tobacco use treatment in dental settings are necessary for the recognition and prevention of smoking.

\section{ACKNOWLEDGEMENTS AND CONFLICT OF INTERESTS}

All authors were active participants in the manuscript.

\section{STATEMENT CONFLICT OF INTEREST:}

There is no conflict of interest involving the authors of this paper.

\section{REFERENCES}

1. World Health Organization. WHO Report on the Global Tobacco Epidemic 2011. Warning about the dangers of tobacco, 2011. http:// whqlibdoc.who.int/publications/2011/9789240687813 eng. pdf?ua01 (Accessed 20 Jan 2017)

2. World Health Organization. WHO Warning about the dangers of tobacco, 2011. http://whqlibdoc.who.int/ publications/2011/9789240687813_eng.pdf?ua01 (Accessed 20 Dec 2016)

3. World Health Organization. WHO The Global Tobacco Epidemic Implementing smoke-free environments 2009 http://www.who. int/tobacco/mpower/2009/en/index.html (Accessed 20 Nov 2016)

4. World Health Organization. WHO - World Health Organization Framework Convention on Tobacco Control 2015 http://www.who. int/fctc/en/ (Accessed 26 May 2016)
5. Dawson GM, Noller JM, Skinner JC. Models of smoking cessation brief interventions in oral health. N S W Public Health Bull. 2013:24(3):131-4.

6. Studts JL, Burris JL, Kearns DK, Worth CT, Sorrell CL. "Providers practice prevention": promoting dental hygienists' use of evidencebased treatment of tobacco use and dependence. J Dent Educ. 2009;73(9):1069-82.

7. Jannat-Khah DP, McNeely J, Pereyra MR, Parish C, Pollack HA, 0stroff J, et al. Dentists' self-perceived role in offering tobacco cessation services: results from a nationally representative survey, United States, 2010-2011. Prev Chronic Dis. 2014;11:E196.

8. Rosa EF, Corraini P, de Carvalho VF, Inoue G, Gomes EF, Lotufo $J P$, et al. A prospective 12-month study of the effect of smoking cessation on periodontal clinical parameters. J Clin Periodontol. 2011;38(6):562-71

9. Tong EK, Strouse R, Hall J, Kovac M, Schroeder SA. National survey of U.S. health professionals' smoking prevalence, cessation practices, and beliefs. Nicotine Tob Res. 2010;12:724-33.

10. Morgan S, Gonzalez E, Hunter E, Ha KH. Tobacco cessation efforts in dentistry: a rural state study. Gen Dent. 2011;59(3):e126-30.

11. Venkatesh S, Sinha DN. Involvement of health professionals in tobacco control in the South-East Asia Region. Indian J Cancer. 2012:49(4):327-35.

12. Parakh A, Megalamanegowdru J, Agrawal R, Hathiwala S, Chandrakar M, Tiwari R, et al. Dental practitioners self reported performance of tobacco cessation counseling interventions: a cross sectional study. Asian Pac J Cancer Prev. 2013;14(10):6141-5.

13. McNeely J, Wright S, Matthews AG, Rotrosen J, Shelley D, Buchholz $M P$, et al. Substance-use screening and interventions in dental practices: survey of practice-based research network dentists regarding current practices, policies and barriers. J Am Dent Assoc. 2013;144(6):627-38.

14. Nordin AS, Kadir RA, Yahya NA, Zakaria H, Rashid RA, Habil MH. Empowering Malaysian dentists to tobacco dependence treatment conduct. Int Dent J. 2014;64(4):206-12.

15. Agaku IT, Ayo-Yusuf OA. A global assessment of knowledge of dental students about nicotine replacement therapy: findings from 43 countries. Eur J Dent Educ. 2014;18(3):154-61.

16. Rosseel JP, Jacobs JE, Hilberink SR, Maassen IM, Segaar D, Plasschaert AJ, et al. Experienced barriers and facilitators for integrating smoking cessation advice and support into daily dental practice. A short report. Br Dent J. 2011;210(7):E10.

17. Studts JL, Burris JL, Kearns DK, Worth CT, Sorrell CL. Evidencebased tobacco cessation treatment by dental hygienists. J Dent Hyg. 2011;85(1):13-21.

18. Davis JM, Ramseier CA, Mattheos N, Schoonheim-Klein M, Compton S, Al-Hazmi N, et al. Education of tobacco use prevention and cessation for dental professionals--a paradigm shift. Int Dent J. 2010;60(1):60-72

19. Ramseier CA, Warnakulasuriya S, Needleman IG, Gallagher JE, Lahtinen A, Ainamo A, et al. Consensus Report: 2nd European Workshop on Tobacco Use Prevention and Cessation for Oral Health Professionals. Int Dent J. 2010;60(1):3-6.

20. Ramseier CA, Burri M, Berres F, Davis JM. The implementation of a tobacco dependence education curriculum in a Swiss Dental Hygiene School - an 8-year review. Int J Dent Hyg. 2013;11(2):142-50.

21. Ajagannanavar SL, Alshahrani OA, Jhugroo C, Tashery HM, Mathews J, Chavan K. Knowledge and perceptions regarding 
nicotine replacement therapy among dental students in Karnataka. $\mathrm{J}$ Int Oral Health. 2015;7(7):98-101.

22. Carr $A B$, Ebbert J. Interventions for tobacco cessation in the dental setting. Cochrane Database Syst Rev. 2012 Jun 13;(6):CD005084. doi: 10.1002/14651858.CD005084.pub3.

23. Virtanen SE, Zeebari Z, Rohyo I, Galanti MR. Evaluation of a brief counseling for tobacco cessation in dental clinics among Swedish smokers and snus users. A cluster randomized controlled trial (the FRITT study). Prev Med. 2015 Jan;70:26-32. doi: 10.1016/j. ypmed.2014.11.005. Epub 2014 Nov 18.

24. Shelley D, Anno J, Tseng T-Y, Calip G, Wedeles J, Lloyd M, et al. Implementing tobacco use treatment guidelines in public health dental clinics in New York City. J Dent Educ. 2011 Apr;75(4):527-33

25. Gordon JS, Andrews JA, Albert DA, Crews KM, Payne TJ, Severson $\mathrm{HH}$. Tobacco cessation via public dental clinics: results of a randomized trial. Am J Public Health. 2010 Jul;100(7):1307-12. doi: 10.2105/AJPH.2009.181214. Epub 2010 May 13.

26. Gordon JS, Andrews JA, Crews KM, Payne TJ, Severson HH, Lichtenstein E. Do faxed quitline referrals add value to dental office-based tobacco-use cessation interventions? J Am Dent Assoc. 2010 Aug;141(8):1000-7.

27. Nasser M. Evidence summary: is smoking cessation an effective and cost-effective service to be introduced in NHS dentistry? $\mathrm{Br}$ Dent J. 2011 Feb 26;210(4):169-77. doi: 10.1038/sj.bdj.2011.117.

28. Matias MA, Steindl SR, Plonka KA, Pukkallus M, Palmer J, Holcombe T, et al. Do school based anti-smoking campaigns delivered by oral health therapists work? Aust Dent J. 2013 Sep;58(3):301-5. doi: 10.1111/adj.12078. Epub 2013 Jul 31.

29. Oberoi SS, Sharma G, Nagpal A, Oberoi A. Tobacco cessation in India: how can oral health professionals contribute? Asian Pac J Cancer Prev. 2014;15(5):2383-91.

30. Ahmady AE, Homayoun A, Lando HA, Haghpanah F, Khoshnevisan MH. Patients' attitudes towards the role of dentists in tobacco cessation counselling after a brief and simple intervention. East Mediterr Health J. 2014 Mar 13;20(2):82-9.

31. Doucette HJ, Maillet PJ, Brillant MG, Tax CL. Dental hygiene students' perceptions of a cultural competence component in a tobacco dependence education curriculum: a pilot study. J Dent Educ. 2015 Jun;79(6):680-5.

32. Awan KH, Hammam MK, Warnakulasuriya S. Knowledge and attitude of tobacco use and cessation among dental professionals. Saudi Dent J. 2015 Apr;27(2):99-104. doi: 10.1016/j. sdentj.2014.11.004. Epub 2015 Jan 29.

33. Fiore MC. Treating tobacco use and dependence: 2008 update U.S. Public Health Service Clinical Practice Guideline executive summary. Respiratory care. 2008;53(9):1217-22.

34. Miller PM, Heideman PW, Ravenel MC, Spangler JG, Mauldin MP, Hill EG, et al. Preliminary development and evaluation of online tobacco and alcohol modules for dental students. J Dent Educ. 2011;75(6):791-6

35. Antal M, Forster A, Zalai Z, Barabas K, Spangler J, Braunitzer G, et al. A video feedback-based tobacco cessation counselling course for undergraduates-preliminary results. Eur J Dent Educ. 2013;17(1):e166-72.

36. Montini T, Schenkel AB, Shelley DR. Feasibility of a computerized clinical decision support system for treating tobacco use in dental clinics. J Dent Educ. 2013;77(4):458-62.
37. Romito L, Schrader S, Zahl D. Using experiential learning and OSCEs to teach and assess tobacco dependence education with first-year dental students. J Dent Educ. 2014;78(5):703-13.

38. Pizzo G, Davis JM, Licata ME, Giuliana G. Assessment of tobacco dependence curricula in Italian dental hygiene schools. J Dent Educ. 2013;77(8):1072-8

39. Dable RA, Wasnik PB, Pawar BR, Bopardikar SS, Nagmode SN. Assessment of professional competency and need of smoking cessation counseling for dental students. J Educ Eval Health Prof. 2014 Oct 5;11:26. doi: 10.3352/jeehp.2014.11.26. eCollection 2014.

40. Hanioka T, Ojima M, Tanaka H, Naito M, Hamajima N, Matsuse R. Intensive smoking-cessation intervention in the dental setting. J Dent Res. 2010;89(1):66-70.

41. Chestnutt IG. Tobacco usage: the role of the dental team in smoking cessation. Dent Update. 2010;37(1):55-6, 9-60, 2.

42. Albert $D$, Ward $A$. Tobacco cessation in the dental office. Dent Clin North Am. 2012;56(4):747-70.

43. Uti 0, Sofola 0. Impact of an educational intervention on smoking counseling practice among Nigerian dentists and dental students. Niger J Clin Pract. 2015;18(1):75-9.

44. Arnett MR, Baba NZ. Improving tobacco dependence education among the Loma Linda University School of Dentistry faculty. J Dent Educ. 2011;75(6):832-8.

45. Arnett MR, Baba NZ, Cheek D. Improving tobacco dependence education for dental and dental hygiene students at Loma Linda University School of Dentistry. J Dent Educ. 2012;76(4):472-8.

46. Andersson P, Westergren A, Johannsen A. The invisible work with tobacco cessation - strategies among dental hygienists. Int J Dent Hyg. 2012;10(1):54-60.

47. O'Donnell JA, Hamilton MK, Markovic N, Close J. Overcoming barriers to tobacco cessation counselling in dental students. Oral Health Prev Dent. 2010;8(2):117-24.

48. Chandrashekar J, Manjunath BC, Unnikrishnan M. Addressing tobacco control in dental practice: a survey of dentists' knowledge, attitudes and behaviours in India. Oral Health Prev Dent. 2011;9(3):243-9.

49. Ehizele A0, Azodo CC, Ezeja EB, Ehigiator 0. Nigerian dental students' compliance with the 4As approach to tobacco cessation. J Prev Med Hyg. 2011;52(1):12-6.

50. Patel AM, Blanchard SB, Christen AG, Bandy RW, Romito LM. A survey of United States periodontists' knowledge, attitudes, and behaviors related to tobacco-cessation interventions. J Periodontol. 2011;82(3):367-76.

51. Uti OG, Sofola 00. Smoking cessation counseling in dentistry: attitudes of Nigerian dentists and dental students. J Dent Educ. 2011;75(3):406-12.

52. Singla A, Patthi B, Singh K, Jain S, Vashishtha V, Kundu H, et al. Tobacco Cessation Counselling Practices and Attitude among the Dentist and the Dental Auxiliaries of Urban and Rural Areas of Modinagar, India. J Clin Diagn Res. 2014;8(9):ZC15-8.

53. Singleton JA, Carrico RM, Myers JA, Scott DA, Wilson RW, Worth CT. Tobacco cessation treatment education for dental students using standardized patients. J Dent Educ. 2014;78(6):895-905.

54. Mackie ZF, Loewen JM, Savaya MG. Evaluation of a Comprehensive Tobacco Dependence Treatment Program: Dental Students' Perceptions of Preparedness and Clinical Practice. J Dent Educ. 2015;79(8):949-58. 
55. Razavi SM, Zolfaghari B, Doost ME, Tahani B. Attitude and practices among dentists and senior dental students in iran toward tobacco cessation as an effort to prevent oral cancer. Asian Pac J Cancer Prev. 2015;16(1):333-8

56. Shaheen S, Reddy S, Doshi D, Reddy P, Kulkarni S. Knowledge, Attitude and Practice Regarding Tobacco Cessation Among Indian Dentists. Oral Health Prev Dent. 2015;13(5):427-34

57. Rindal DB, Rush WA, Schleyer TK, Kirshner M, Boyle RG, Thoele $\mathrm{MJ}$, et al. Computer-assisted guidance for dental office tobaccocessation counseling: a randomized controlled trial. Am J Prev Med. 2013;44(3):260-4

58. Ostroff JS, Li Y, Shelley DR. Dentists United to Extinguish Tobacco (DUET): a study protocol for a cluster randomized, controlled trial for enhancing implementation of clinical practice guidelines for treating tobacco dependence in dental care settings. Implement Sci. 2014;9:25

59. Amemori M, Korhonen T, Kinnunen T, Michie S, Murtomaa H Enhancing implementation of tobacco use prevention and cessation counselling guideline among dental providers: a cluster randomised controlled trial. Implement Sci. 2011;6:13.

60. Gonseth S, Abarca M, Madrid C, Cornuz J. A pilot study combining individual-based smoking cessation counseling, pharmacotherapy, and dental hygiene intervention. BMC Public Health. 2010;10:348.

61. Shelley D, Wright S, McNeely J, Rotrosen J, Winitzer RF, Pollack H, et al. Reimbursing dentists for smoking cessation treatment: views from dental insurers. Nicotine Tob Res. 2012;14(10):1180-6.

62. Svetanoff E, Romito LM, Ford PT, Palenik CJ, Davis JM. Tobacco dependence education in U.S. Dental assisting programs' curricula J Dent Educ. 2015;79(4):378-87.

63. Pau A, Olley RC, Murray S, Chana B, Gallagher J. Dental hygienists self-reported performance of tobacco cessation activities. Oral Health Prev Dent. 2011;9(1):29-36.

64. Prakash P, Belek MG, Grimes B, Silverstein S, Meckstroth R, Heckman B, et al. Dentists' attitudes, behaviors, and barriers related to tobacco-use cessation in the dental setting. J Public Health Dent. 2013;73(2):94-102

65. Ford P, Tran P, Keen B, Gartner C. Survey of Australian oral health practitioners and their smoking cessation practices. Aust Dent J. 2015;60(1):43-51; quiz 128.

66. Sinha DN, Rinchen S, Palipudi KM, Naing Shein NN, de Silva P, Khadka BB, et al. Tobacco use, exposure to second-hand smoke, and cessation training among the third-year medical and dental students in selected Member States of South-East Asia region: a trend analysis on data from the Global Health Professions Student Survey, 2005-2011. Indian J Cancer. 2012;49(4):379-86.

67. Kadanakuppe S, Aradhya S. Survey of patient opinion on tobacco cessation counseling and services in a dental teaching institution and hospital. Oral Health Prev Dent. 2013;11(2):175-80.

68. Ford PJ, Tran P, Cockburn N, Keen B, Kavanagh DJ, Gartner C. Survey of dental clinic patients: smoking and preferences for cessation support. Aust Dent J. 2016;61(2):219-26.

69. Needleman IG, Binnie VI, Ainamo A, Carr AB, Fundak A, Koerber A, et al. Improving the effectiveness of tobacco use cessation (TUC) Int Dent J. 2010;60(1):50-9.

70. Carson KV, Verbiest ME, Crone MR, Brinn MP, Esterman AJ, Assendelft WJ, et al. Training health professionals in smoking cessation. Cochrane Database Syst Rev. 2012;5:CD000214.

71. Ramseier CA, Suvan JE. Behaviour change counselling for tobacco use cessation and promotion of healthy lifestyles: a systematic review. J Clin Periodontol. 2015;42 Suppl 16:S47-58.

72. Omana-Cepeda C, Jane-Salas E, Estrugo-Devesa A, ChimenosKustner E, Lopez-Lopez J. Effectiveness of dentist's intervention in smoking cessation: A review. J Clin Exp Dent. 2016;8(1):e78-83.

73. Stassen LF, Hammarfjord 0. Smoking cessation and the role of the dental practitioner. J Ir Dent Assoc. 2015;61(2):90-2.

74. Neff JA, Gunsolley JC, Alshatrat SM. Topical trends in tobacco and alcohol articles published in three dental journals, 1980-2010. J Dent Educ. 2015;79(6):671-9.

75. Lancaster T, Stead LF. Individual behavioural counselling for smoking cessation. Cochrane Database Syst Rev. 2017;3:Cd001292.

76. World Health Organization. WHO. Tobacco Free Initiative (TFI) 2011 http://www.who.int/tobacco/en/ (Accessed 20 Jan 2017)

77. World Health Organization. WHO. Framework Convention on Tobacco Control.: World Health Organization; 2016 http://www. who.int/fctc/en/. (Accessed 20 Dec 2016)

78. Tami-Maury I, Aigner CJ, Hong J, Strom S, Chambers MS, Gritz ER. Perception of Tobacco use Prevention and Cessation Among Faculty Members in Latin American and Caribbean Dental Schools. J Cancer Educ. 2014;29(4):634-41.

\section{Janete D. Almeida (Corresponding address)}

São Paulo State University (Unesp)

Institute of Science and Technology - São José dos Campos

Department of Biosciences and Oral Diagnosis - SP - Brazil.

Address: Av. Francisco José Longo, 777 - São Dimas

CEP: 12245-000

São José dos Campos, São Paulo, Brazil.

Date submitted: 2017 Jun 05

E-mail address: janete@fosjc.unesp.br
Accept submission: 2017 Sep 01 